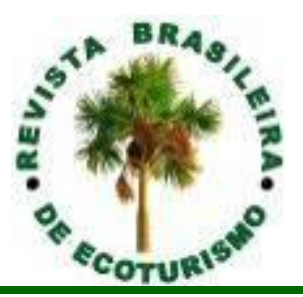

\title{
Patrimônio cultural e representações sociais do turismo em São Paulo, Valéria (AM)
}

\section{Cultural heritage and social representations of the tourism in São Paulo, Valéria (AM, Brazil)}

\author{
Naia Maria Guerreiro Dias
}

RESUMO: Valéria (AM) é uma localidade amazônica que está situada na zona rural do município de Parintins/AM, fronteira com o estado do Pará. Possui um rico e diversificado atrativo turístico natural e cultural. Nela encontram-se dois sítios arqueológicos identificados por AM-PT-01 e AM-PT02, sobre os quais estão assentadas as comunidades tradicionais São Paulo e Santa Rita da Valéria (AM). Além desses patrimônios culturais há uma sociodiversidade de patrimônios materiais e imateriais que tem atraído desde a década de 1970, turistas tanto de origem nacional e internacional, fato que permanece até a contemporaneidade. O presente estudo consistiu em compreender as representações sociais que os moradores do sítio arqueológico São Paulo/ Valéria construíram sobre o turismo na localidade. Para isso, foi realizada a pesquisa de campo de cunho qualitativa, norteada pelos pressupostos teórico metodológico das Representações Sociais (RS), os quais, enquanto formas de conhecimento, são ancorados na esfera cognitiva e, sendo o conhecimento um produto social, não tendem a ser desvinculados do contexto social no qual emergem, circulam e são modificados (ABRIC, 1994). Destaca-se que a prática do turismo em áreas arqueológicas requer planejamento e engajamento de toda a comunidade, sendo de fundamental importância que os moradores conheçam e valorizem sua história, tendo o turismo como uma forma de contribuir com a manutenção e preservação do sítio arqueológico atrelando o que propõe Bartholo (2014) a economia com o mercado e não para o mercado. É portanto, um estudo que suscita reflexão sobre a complexidade da prática do turismo em áreas patrimoniais de um sítio arqueológico da Amazônia.

PALAVRAS-CHAVE: Patrimônio Cultural; Turismo; Sítio Arqueológico; Representações Sociais. 


\section{ABSTRACT}

Valéria (AM, Brazil) is an Amazonian place that it is placed in the rural area of the municipal district of Parintins (AM, Brazil), border with the state of Pará. It possesses a rich one and diversified natural and cultural tourist attraction. In her they are two identified archeological ranches for AM-PT-01 and AM-PT-02, on which the traditional communities are seated São Paulo and Santa Rita of Valéria (AM, Brazil). Beyond of those cultural heritages there is a partner diversity of material and immaterial patrimonies that it has been attracting since the decade of 70 , tourists so much of national and international origin, fact that stays until the contemporary. The present study consisted of understanding the social representations that the residents of the archeological ranch São Paulo/Valéria built about the tourism in the place. For that, the qualitative research of stamp field was accomplished, orientated by the methodological of the Social Representations theoretical presuppositions (RS), the ones which, while knowledge forms, they are anchored in the cognitive sphere and, being the knowledge a social product, they don't tend to be disentailed of the social context in which they emerge, circulate and they are modified (ABRIC, 1994). he/she Stands out that the practice of the tourism in archeological areas requests planning and engagement of the whole community, being of fundamental importance that the residents know and value his/her history, tends the tourism as a form of contributing with the maintenance and preservation of the archeological ranch harnessing what proposes Bartholo (2014) the economy with the market and not for the market. $E$ therefore, a study that raises reflection about the complexity of the practice of the tourism in patrimonial areas of an archeological ranch of the Amazonian.

KEYWORDS: Cultural Heritage; Tourism; Archeological Ranch; Social Representations.

\section{Introdução}

A Amazônia, desde o processo de colonização, tem sido considerada região de fascínio e encantamento (COSTA, 2001). Navegantes, naturalistas e expedicionários cientistas ou clérigos fizeram viagens no sentido de conhecer e relatar a diversidade da rica fauna, flora e o modo de vida das pessoas do lugar. Foram viagens que, guardadas as proporções, mesclaram turismo e aventura laboratorial e experimentação na região, então em processo de invasão e destroçamento sociocultural.

Por ter características singulares e complexas, a Amazônia configurase em nicho turístico para diversas segmentações do turismo. É uma relação ambígua, dado que ao Estado interessa o fomento de atrativos econômicos que tenham valor de mercado e ao mesmo tempo interessa também aos nativos essa valoração. Mas a forma como a prática tem sido implementada acaba por prejudicar, em certa medida, ambientes e modos de vida de comunidades locais. 
A perspectiva deveria ser justificada como negócio promissor para 0 socioambiente, instrumentalizando mecanismos de preservação e conservação dos patrimônios materiais e imateriais, aliados a temas educativos e de forte ancoragem na cidadania e preservação dos patrimônios culturais.

Para compreensão da atividade turística no sítio arqueológico de São Paulo da Valéria, zona rural do município de Parintins Amazonas, buscou-se fazer a pesquisa norteada pela teoria das representações sociais, a qual configura-se como um conjunto de ideias, opiniões, valores, preconceitos e estereótipos que os indivíduos têm sobre um objeto social (MOSCOVICI, 1976).

\section{Patrimônio Cultural}

A definição de patrimônio é relativa, partindo de diferentes perspectivas: legais, afetivas, econômicas, territoriais ou socioculturais (VIANNA, 2008). Na Constituição de 1988, a definição de patrimônio integra a noção de patrimônio cultural. No documento, patrimônios culturais brasileiros são descritos como bens de natureza material e imaterial, tomados individualmente ou em conjunto, portadores de referência à identidade, ação, memória e conformação de grupos da sociedade brasileira (PAIM, 2010).

No contexto acadêmico, textos de Ciências Sociais e Humanas abordam ao longo do processo histórico diferentes conceituações sobre patrimônio cultural em decorrência de mudanças em concepções sobre o ambiente na sociedade (MACHADO, 2004). De modo que patrimônio, hoje, é compreendido como ente, coisa ou lugar de memória. A caracterização conceitual encerra-se onde a dimensão inter-relacional das pessoas com o território e a mutualidade concorre para a atribuição de significados (NORA, 1997).

Podem ser considerados patrimônios uma fotografia, uma casa, um sítio arqueológico, uma dança, uma música etc. Registros na Amazônia, especificamente, podem ser identificados ao ponto em que se concebem práticas e representações de pessoas, lugares e coisas, destacando-se aspectos referentes a permanências e transformações ocorridas em determinados contextos socioculturais

O significado de patrimônio tende a recair atualmente tanto sobre aspectos ideais e valorativos da forma de vida de povos quanto sobre a questão material. Conceituar patrimônio, desta feita, é essencialmente um ato de estabelecimento de conexão significativa com mosaicos que conferem singularidade a diversas e complexas sociedades.

No passado, a noção de patrimônio foi ancorada no antagonismo natureza e cultura, sendo construída como o resultado de expressões metafísicas ocasionadas pela ação humana (GONÇALVES, 2002). Mas impasses causados pela dualidade fomentaram a superação do dilema e foram feitas restituições do conceito de patrimônio e, por conseguinte, do planejamento das respectivas políticas públicas. 
Patrimônio passou a ser entendido não apenas como obra produzida por ação humana. Incluíram-se contextos naturais que passaram a abarcar cenários de memórias e identidades sociais. Com a atuação significativa do Iphan, alargou-se o leque de preocupações com manifestações culturais e fazeres. Estes passam a ser considerados bens de culturais de natureza imaterial.

Quando nos referimos ao conceito de patrimônio, apreendido como expressão mais profunda da "alma dos povos" e como "legado vivo" que recebemos do passado, vivemos no presente e transmitimos às gerações futuras, admitimos que o patrimônio é historicamente construído e conjuga o sentido de pertencimento dos indivíduos a um ou mais grupos (PELEGRINI, 2007, p.14)

Patrimônio na perspectiva de Gonçalves (2002) é uma categoria de pensamento extremamente relevante para a vida social e mental da coletividade de qualquer sociedade. "Ainda que possamos usar a categoria patrimônio em contextos muito diversos, é necessário adotar certas precauções. É preciso contrastar cuidadosamente as concepções do observador e as concepções nativas" ( GONÇALVES, 2002, p.24).

Por isso que é importante ressaltar que a noção de patrimônio para um grupo, está associada aos elementos construídos pela coletividade, como por exemplo, a história, a memoria, a identidade ou seja, aos fatores que lhes conferem referenciais de pertencimento a uma determinada comunidade.

A esse respeito Leite (2011, p.58) propõe :

Ampliar a discussão sobre patrimônio, englobando as manifestações, o fazer e o saber fazer, torna-se um item essencial na agenda do novo século, permeando todas as discussões, sejam elas políticas, econômicas ou sociais. A noção de patrimônio passou a incluir os testemunhos, grandes ou pequenos, dos valores humanos e a responsabilidade atual está diretamente ligada às gerações futuras, ao que será definido como história-memória pelos diversos atores sociais.

Patrimônio está estritamente ligado às experiências construídas, aos mitos, as histórias, as narrativas locais, ao modo de vida, a uma série de coisas consagradas e que tem valor para uma pessoa ou para a comunidade. Sendo que esse sentimento de valoração é transmitido de geração a geração e que tende a fortalecer ainda mais o sentimento pertencimento em meio a rupturas e continuidades. "O patrimônio é uma maneira de viver as rupturas, de reconhecê-las e reduzi-las, referindo-se a elas, elegendo-as, produzindo semióforos..." (HARTOG, 2006, p. 272).

Convém ponderar ainda acerca da noção de patrimônio proposta por Caiado(2001, p. 59) o qual afirma que: "é fundamental que haja 
reconhecimento da diversidade cultural, a partir das peculiaridades de cada local, pois assim será fortalecida a identidade entre o indivíduo e seu grupo entre este, o meio ambiente e a sociedade".

Entretanto, não basta apenas compreender a concepção de patrimônio ou suas diferentes compreensões epistemológicas, torna-se fundamental discutir sobre os mecanismos de preservação dos diferentes bens patrimoniais sejam eles materiais ou imateriais.

Remontam as duas primeiras décadas do século $X X$, a preocupação com o patrimônio, entretanto naquela conjuntura, a concepção do seria preservado estava mais direcionado aos grandes empreendimentos arquitetônicos e voltados para os valores da elite. A partir de um grande debate sobre a importância de preservar o patrimônio foi criado o serviço do Patrimônio Histórico e Artístico Nacional - SPHAN em 1937 (PAIM, 2010).

Com esse tipo de tombamento - os dos prédios da elite- foi negado 0 direito a preservação da memória para a maioria dos brasileiros, em que a maioria da população não se reconhecia no patrimônio preservado, pois os mesmos não tinham vínculo com suas vidas.

Em 1970, o SPHAN, passou a denominar-se Instituto do Patrimônio Histórico artístico e Nacional (Iphan), no qual já passa a ser discutido a questão do turismo cultural, o enfoque agora consiste em revitalizar 0 patrimônio para a questão econômica, a preservação consistia em atrair turistas para a visitação e consequentemente fomentar a geração de renda local.

Posteriormente no final da década de 1970, em 1979, o IPHAN passou por reformulações administrativas e começou a alargar o leque de preocupações com diferentes manifestações culturais, saberes e fazeres do povo brasileiro, a comunidade foi chamada a participar do processo de definição do que seria patrimônio. Tais abordagens foram consolidadas na Constituição de 1988.

No entanto, a mudança mais significava no âmbito da discussões do IPHAN, ocorreu em 04 de agosto de 2000, com a publicação do Decreto $\mathrm{n}^{\circ}$ 3551 , o qual instituiu também o registro de bens culturais de natureza imaterial. Sendo que passaram a ser reconhecidos como patrimônio as ações, os saberes e fazeres que não podem ser expressos de forma material.

Nesse sentido destaca-se que no Brasil atualmente há diversas instituições preocupadas em preservar o patrimônio. Em âmbito nacional tem o Instituto Brasileiro do Meio Ambiente e dos Recursos Naturais Renováveis (Ibama), ligado ao Ministério do Meio Ambiente (MMA), e o Instituto do Patrimônio Histórico e Artístico Nacional (Iphan), ligado ao Ministério da Cultura (MEC);

Abordando um pouco sobre os órgãos de proteção do Estado do Amazonas, tem a Secretaria de Estado da Cultura (SEC). E na esfera municipal, Parintins/AM tem a Secretaria Municipal de Cultura e Turismo e o Instituto Memorial de Parintins (Impin). Ambos possuem missão de salvaguardar patrimônios da região enquanto bens potencializadores de autoimagem e qualidade de vida, via aquisição de conhecimentos para 
práticas de cidadania. Dentre eles, destaca-se o sítio arqueológico da Serra de Valéria, onde comunidades estão assentadas e realizam interações diversificadas com seu espaço.

\section{O turismo e a relação com sítios arqueológicos}

Por ser atividade diversificada, o turismo pode ser desenvolvido em diferentes áreas e contextos. Nesse cenário, destaca-se a prática do turismo em regiões de grande concentração de vestígios arqueológicos, tendo em vista o enorme interesse de destinos turísticos a essas localidades.

A arqueologia da região Amazônica sempre chamou a atenção tanto de pesquisadores quanto de turistas - que se admiram das peças indígenas ancestrais encontradas expostas ao solo, abaixo dele ou até guardadas em casas de moradores locais -, os quais colecionam essas relíquias arqueológicas e as utilizam como um mecanismo de economia doméstica.

O olhar sobre o exotismo e a beleza contidos nos artefatos arqueológicos da Amazônia tem sido ação praticada desde o final do século XIX e na primeira metade do século XX. Já na segunda metade do século XX, foi havendo alteração paulatina nessa postura, com a consolidação da arqueologia como ciência e disciplina a serviço da população (FIGUEIREDO, 2007).

Mas a atividade do turismo nesses locais, que são patrimônios culturais, incorre potencialmente em duas situações extremas: i) pode vir a colaborar com a preservação e a memória social do lugar e ii) pode vir a gerar problemática relacionada ao turismo predatório. Sobre esses tópicos, Meneses (2007) propõe que antes de se efetivar o turismo em sítios arqueológicos faz-se imprescindível a reflexão acerca de outras três questões fundamentais.

A primeira consiste em analisar cautelosamente políticas públicas para o bem público e não só para o poder público; o segundo ponto é a própria ideia de passado arqueológico, que caracteriza a demanda habitual do turista e a resposta que lhe é retornada; e por fim se apresenta a condição majoritária do patrimônio arqueológico, uma vez que o interesse dos turistas não está no espaço enquanto ambiente patrimonial, mas nos artefatos presentes nesses ambientes.

O turismo efetivado apenas como força de mercado pode provocar a teatralização da cultura, a exclusão da comunidade e a seleção de patrimônios escolhidos por meros interesses econômicos, transformando os comunitários dos locais em atores cênicos, performáticos tal e qual seu ambiente e seus costumes. Porquanto, visitar sítios arqueológicos está mais próximo ao fato de se encontrar diante de lugares de ancestralidade, os quais remetem a formas de viver.

Com efeito, a discussão sobre como possibilitar o uso de sítios arqueológicos para o turismo e assegurar a preservação ainda se efetiva. Questão acerca do exposto são especificadas de tal modo: "como integrar o 
patrimônio à rotina das comunidades no sentido de auxiliá-las no desenvolvimento de renda e inclusão social?".

Pardi (2007) afirma que essa questão é bastante complexa, sendo fundamental a compreensão da cultura no turismo em áreas patrimoniais, como é o caso dos sítios arqueológicos. Isso possibilita a boa interação entre turista e lugar visitado, vindo a mitigar impactos negativos do turismo nessa ambiência sociohistórica.

A ambiência vem a ser, de acordo com Brasil (2006), uma conceituação não apenas voltada para aspectos físicos de determinado lugar. Ela está diretamente ligada ao social, consolidada nas interações entre as pessoas, possibilitando um ambiente mais harmonioso a todos. Para isso, faz-se importante a compreensão de três eixos componentes da ambiência: 0 primeiro diz respeito à confortabilidade, em que se busca valorizar o meio onde os sujeitos interagem; o segundo versa sobre a subjetividade impregnada pela ação e reflexão que ocorre no espaço; e o terceiro vislumbra o espaço como elemento que facilita mudanças ocorridas em relações sociais.

Por ambiência, pode-se entender ainda tudo o que está a volta de um determinado indivíduo ou grupo social, mas devendo-se contextualizar o condicionamento de suas existências, em que apesar de haver uma compreensão singular, há de modo coletivo uma identificação ou uma representação simbólica, na qual as relações podem vir a ocorrer tanto nas escalas do local quanto do global (REGO, 2010).

Na Amazônia, há conjuntos variados de sítios arqueológicos que já vem sendo utilizados como parte do destino turístico para a região. Mas o uso turístico requer antes de tudo planejamento, análise do impacto sobre a área e estimativas de consolidação de políticas públicas em função da mudança do local e da comunidade de participantes que está ativamente na gestão operacional do sítio.

"Os princípios do turismo cultural envolvem o descobrimento do sentido, os símbolos e os significados da cultura para potencializar os atributos, o respeito a identidade e a memória dos grupos formadores da cultura e sua dinâmica própria" (PARDI, 2007, p. 326). Paralelo a isso, podese pensar também a viabilização econômica da manutenção desses bens.

A arqueologia, além de proporcionar o conhecimento da população que vive no sítio, proporciona que se conheçam as características dos povos e das culturas que ocuparam a região em diferentes contextos históricos e isso envolve a interface com diferentes áreas do conhecimento (BARRETTO, 2007).

A complexidade do turismo em áreas arqueológicas pressupõe a atuação significativa de comunitários, tendo em vista minimizar impactos negativos. Uma das preocupações com as atividades turísticas em sítios arqueológicos habitados é a comercialização de artefatos pertencentes a uma memória social que precisa ser preservada (FUNARI; PELEGRINI, 2006; MENESES, 2007; LIMA 2013).

Todavia, contrária a isso, a prática do turismo local de modo planejado pode vir a ajudar na manutenção e preservação de vestígios e artefatos. E 
esse planejamento tende a requerer a adaptação da visitação a especificidades locais, a partir, por exemplo, da construção de estruturas para acesso a ambientes patrimoniais, com placas sinalizadoras de áreas frágeis, controle de visitação e informações sobre a história do local. A musealização e turistificação de zonas próximas ao sítio ou no próprio sítio é fator primordial (FIGUEIREDO, 2007).

Para Duarte Cândido (2014, p. 19)

[...] o processo de musealização ocorre a partir de uma seleção e atribuição de sentidos feita dentro de um universo patrimonial amplo, resultado de um recorte formado por um conjunto de indicadores da memória ou referências patrimoniais tangíveis ou intangíveis, naturais ou artificiais indistintamente. Feita a seleção, estas referências ingressam em uma cadeia operatória que corresponde ao universo de aplicação da museologia - museografia. Preservação, portanto, é tomada como equivalente a processo de musealização, e é realizada pela aplicação de uma cadeia operatória formada por procedimentos técnico-científicos de salvaguarda e de comunicação patrimoniais, em equilíbrio.

A musealização refere-se não a instituições edificadas, mas a um conjunto de valores culturais e simbólicos de determinada comunidade, a qual participe de modo efetivo de atividades desenvolvidas em seu ambiente, demonstrando sentimento de pertencimento ao lugar. Daí que, ao "turistificar" o patrimônio, a comunidade pode tender a considerar reflexões propostas por Morais (2012, p. 4), que pondera sobre "como turistificar esses espaços sem que eles percam suas funções de lugares, onde é possível dialogar com a alteridade e com a própria identidade sociocultural".

Apesar da complexidade que envolve a relação entre o turismo e o patrimônio, é possível, a partir do planejamento de forma participativa e a inclusão da comunidade local no desenvolvimento do turismo, obter resultados positivos da atividade turística em áreas patrimoniais.

\section{Patrimônio Cultural e Representações Sociais do turismo em São Paulo, Valéria (AM)}

A região da Valéria tem como cartão postal um rico e diversificado paisagismo natural e cultural que lhe confere tamanha beleza. Ao longo do processo histórico, essa paisagem sempre chamou a atenção de quem navegava pelas águas do rio Amazonas. Nos relatos de Von Martius (1979), acerca de suas viagens pelo Brasil, entre 1817 a 1832, consta o seguinte:

No dia $1^{\circ}$ de outubro de 1820 , alcançamos Parintins, algumas palhoças ao sopé de uma colina de uns 200 pés de altura, coberta de mata virgem densa, que, de certo modo, pode ser 
considerado como ponto limítrofe entre as províncias do Pará e do Rio Negro (VON MARTIUS apud SAUNIER, 2003, p. 43).

Para Azevedo Filho (2013), o pesquisador alemão estava se referindo à região da Valéria, tendo como uma de suas paisagens naturais a Serra da Valéria, ou de Parintins, como muitos moradores locais a denominam. Importa frisar, nesse contexto, que a Valéria é retratada como espaço natural que atrai diferentes indivíduos ou agrupamentos, seja para contemplar a beleza paisagística do lugar ou para realizar outras atividades, como caça, pesca e mesmo lazer. Além disso, possui dois importantes sítios arqueológicos catalogados e registrados por Hilbert e Hilbert (1979) - como AM-PT-01 Santa Rita e o AM-PT-02 São Paulo.

Por essa razão, a pesquisa tem apontado que a prática da atividade turística na localidade tem se desenvolvido a partir do interesse de visitantes oriundos de diferentes nacionalidades, que almejam conhecer a região descrita nos relatos de importantes pesquisadores da Amazônia, bem como pela busca do conhecimento dos modos de vida das pessoas da localidade.

Como atrativos turísticos locais os moradores apresentam:

A gente tem como atrativo para o turismo muitas coisas, por exemplo: a serra (figura 15), que é muito bonita, que pode ser vista de longe por quem passar pelo rio Amazonas. A visão lá de cima dona, é muito linda! Dá pra ver todo o rio Amazonas, do nascer ao por do sol, o outro lado do rio (...) A serra da Valéria é um lugar de muito encantamento. Nela tem umas estradas que a gente fez para subir tanto a gente que mora aqui como para vocês visitantes e também os turistas. $\mathrm{Na}$ própria serra tem o sítio arqueológico, que até a chegada dos arqueólogos aqui a gente nem sabia se era esse tal de sítio arqueológico (risos), mas nele tem muito dessas coisas aí dos índios que moravam aqui também, como as panelas, cacos de vasilhas, umas caretinhas. Ah! isso antigamente os turistas gostavam de ver muito. Hoje até que não mais...É, também tem as árvores, as plantas, os medicamentos, que a gente usa pra se curar, tudo isso eu vejo que tem trazido as pessoas pra virem pra cá. E é assim que durante a presença de navios estrangeiros a gente tem feito (GLÓRIA ANDRADE, 65 ANOS, MORADORA DE SÃO PAULO, ENTREVISTA REALIZADA EM ABRIL DE 2016).

Um outro morador, o senhor Otávio, vê demais atrativos turísticos e ele diz:

O turismo aqui acontece pelo fato de ter muita água boa pra beber, por causa da beleza do lago, dos peixes, dos pássaros, dos passeios de canoa. O contato com os animais daqui da Valéria, que eu acho que não tem por lá igual aos 
daqui tem trazido muita gente pra cá pra Boca. Tem também a vitória-régia, que é uma planta da água muito fotografada na época da cheia. Agora que tá seco não aparece muito, mas na cheia é uma beleza! Então eu vejo que a nossa natureza é muito bonita e isso tem mantido sempre a presença dos turistas. Também tem o artesanato, a festa do santo. Os turistas que vem dos navios eles entram nas nossas casas pra ver como a gente mora, tiram fotografia, e sempre deixam nas nossas casas alguns dólares em papel ou moeda e alguns outros presentes. Mas a gente sente falta de apoio, dona, a gente quer apreender mais a fazer essa atividade do turismo, porque a gente faz sem muita estrutura (ENTREVISTA REALIZADA EM NOVEMBRO DE 2015).

Tomando como ponto de análise as entrevistas dos moradores e também os registros das observações realizadas em campo, nota-se que há uma imagem positiva do sítio arqueológico São Paulo da Valéria como um todo e no que tange ao conjunto paisagístico que constitui a região da Valéria, seja pela beleza natural, pelo reconhecimento da sua cultura, reforçada pela prática da pesca, pela utilização de saberes tradicionais, artesanato, culinária e outros elementos que constituem representações sobre o turismo nessa localidade amazônica.

Para Jodelet (1993, p. 55), "as representações sociais intervêm em processos tão variados quanto a difusão e a assimilação dos conhecimentos, no desenvolvimento individual e coletivo, na definição das identidades pessoais e sociais, na expressão dos grupos e nas transformações sociais". Em São Paulo da Valéria, com a inserção da prática do turismo, houve uma transformação de sua realidade, pois os habitantes dessa comunidade tradicional, que antes viviam apenas de agricultura e pesca de subsistência, foram adquirindo conhecimentos e os adaptaram em seu contexto social.

Há que se destacar que o conjunto de atrativos turísticos locais tem promovido a presença constante de visitantes e turistas na região da Valéria, dado que 0 turismo na localidade tem crescido bastante na contemporaneidade em função dos meios de comunicação e transporte. Em decorrência da atividade ocorrer em áreas patrimoniais - os sítios arqueológicos - ela requer planejamento adequado, a fim de que o aspecto econômico não se sobreponha a aspectos socioculturais inerentes a comunitários, vindo a prejudicar a memória e a história do lugar. $\mathrm{O}$ que poderia vir a se tornar uma imagem negativa da prática turística.

O turismo é uma das atividades pode vir a ser aliada na proteção de patrimônios culturais, sejam eles materiais ou imateriais, considerando práticas e representações de diferentes grupos sociais, aquilo que os identifica como suas atividades de subsistência, folguedos, religiosidade, artesanato, gastronomia, festas típicas, rituais, folclore, música, espaço de sociabilidade, sítios arqueológicos (FUNARI, 2003; PELEGRINE, 2007; GONÇALVES, 2002).

O crescimento do turismo em áreas arqueológicas está associado ao crescente fenômeno da globalização, demandando da parte das sociedades 
que recepcionam a necessidade de se reconhecer como portadora de uma memória social crivada por identidades, visando ressignificar patrimônios. Por sua vez, grupos sociais tendem a demonstrar interesse pelo modo de vida de sociedades tradicionais (LEITE, 2013) e, nesse ínterim, é importante destacar que em falas de entrevistados de percebe que turistas demonstram interesse pela cultura local. Mas como possibilitar o usufruto do patrimônio sem provocar danos ao socioambiente? Será que moradores locais têm atentado para essa situação? Sobre a inquietação, um dos entrevistados respondeu:

\begin{abstract}
Essa questão é bem complicada (...) porque na verdade quando a gente está em atividades aqui na Boca, na época da presença dos navios estrangeiros, a gente quer vender nossos produtos, os artesanatos, as comidas, mostrar nossos animais etc. Queremos tirar um lucro, já que esse é um único momento que tem para conseguir um dinheirinho a mais. $E$ sobre os patrimônios daqui a gente não discute muito. Só mesmo sobre as caretinhas que a gente teve umas orientações do que fazer, com os estudiosos que vieram pra cá. Porque a senhora sabe, se eu não sei o que é uma coisa, se ela tem valor, como que vou zelar? Cuidar? Assim era com esses cacos, eles eram só caretinhas, cacos, coisas que a gente achava no terreiro, nos roçados. E no início do turismo aqui vimos que os turistas tinham interesse e que ainda pagavam por aquilo, a gente passou a colocar nas mesas pra eles verem... é que vender a gente não vende mais não. Porque foi mostrado que os turistas querem ver o que é nosso inteiro e não destruído (GLÓRIA ANDRADE, MORADORA DE SÃO PAULO, ENTREVISTA REALIZADA EM ABRIL DE 2016).
\end{abstract}

O interesse econômico parece evidente na fala da moradora, mas ao mesmo tempo também há o reconhecimento da importância do cuidado com o patrimônio. Nas observações em lócus, identificou-se que moradores possuem práticas diferenciadas em relação ao sítio arqueológico onde vivem. Uns tem sentimento de pertencimento ao lugar; outros utilizam o espaço somente como meio de obtenção de dinheiro com a prática do turismo; e há aqueles que entendem a importância do evento turístico para melhorar sua fonte de renda, mas que compreendem que também devem preservar o lugar. Mas porquê dessa atitude contraditória? Dados apontam que vários fatores impulsionam a situação, como a falta orientação ou realização de formação continuada para moradores sobre educação patrimonial, ausência de formação sobre que tipo de turismo desenvolver ou como bem implementar práticas que já se efetivaram como atividade do calendário de eventos locais e mesmo falta de ações positivas para a construção de uma prática social.

Interpretando o fenômeno, tem-se uma questão: como o turismo pode vir a contribuir com a manutenção do lugar? Meneses (2007) ressalta a importância de se levar em consideração políticas públicas pensadas para o bem coletivo e em razão da arqueologia local. A perspectiva é repassar características referentes às condições de manutenção de artefatos 
arqueológicos presentes, os quais naturalmente são objeto de interesse de turistas. Dialogando com o apontamento, Funari (2003) ressalta que o aproveitamento para o turismo em áreas arqueológicas não deve estar pautado apenas no fator econômico, mas levar em consideração políticas que envolvam a coletividade, permitindo que bens arqueológicos adquiram sentido para comunitários e que isso possa ser uma experiência partilhada em visitações.

A utilização do patrimônio com finalidade turística gera diferentes atividades econômicas, divisas, empregos e serve em parte como estratégia para o desenvolvimento de uma localidade ou região. A valorização do patrimônio arqueológico por meio de projetos que busquem conservação e exposição de forma controlada e adoção de mecanismos de visitação monitorada, através do turismo arqueológico, pode auferir recursos que poderão ser revertidos para a sua conservação de forma sustentável e também incentivar a sua proteção (MENESES, 2007; MARTINS, 2008).

Pode-se entender que a representação do turismo construída pelos moradores de São Paulo está contida numa crença tanto individual quanto coletiva acerca da possibilidade de transformação do espaço natural e cultural em lugar turístico, otimizando relações sociais e econômicas. Ao mesmo tempo, estão presentes em conteúdos apresentados nos relatos imagens tanto positivas quanto negativas do turismo na localidade, onde há forte indício de turismo exploratório, pautado em obter lucros imediatos, em detrimento do aproveitamento dos valores e recursos culturais da comunidade como estímulo à reafirmação da identidade cultural, da ressignificação dos patrimônios e viabilizando a possibilidade de melhorar a distribuição de renda a todos os moradores.

\section{Considerações Finais}

O estudo sobre o patrimônio cultural e turismo em Valéria evidenciou que o modo como o turismo foi sendo inserido na comunidade implicou em modificações ocorridas tanto o modo de vida como as relações sociais locais. Os moradores foram construindo e (des)construindo diferentes maneiras de compreender sua realidade, em função da conjuntura em que se apresentou essa prática. Isso leva a crer que esses elementos são formadores de uma identidade coletiva e socioterritorial da comunidade, sendo a partir dela que as relações vão se estabelecendo nesse espaço e os indivíduos vão atribuindo significados às coisas e construindo novas representações sociais MOSCOVICI, 2003, BAUER, 1997, JODELET, 2002).

As TRS possibilitaram uma análise mais consistente dos dados obtidos uma vez que a representação social pode ser entendida como uma forma de conhecimento, socialmente elaborada e partilhada, tendo uma visão prática e 
concorrendo para a construção de uma realidade comum a um conjunto social (JODELET, 2001).

A partir da seleção dos depoimentos, foi possível elucidar pelo víeis das representações sociais, uma imagem tanto positiva como negativa apresentada pelos moradores de São Paulo. De um modo positivo, estes representam o sítio como um lugar que se destaca pelas belezas naturais, a serra, a fauna, a flora, os animais, e mesmo pelo reconhecimento da sua cultura, reforçada pela prática da pesca, da caça e a utilização desse produto na sua alimentação cotidiana. Além disso, a tranquilidade e a receptividade das pessoas que residem no local ganha uma destaque significativo e singular.

Contrapondo-se a essa visão, identificou-se os aspectos negativos presentes em práticas que evidenciam o sentimento de desamparo à comunidade e abandono ao seu lugar de vivência, e supervalorização da questão econômica ainda que sazonal. No entanto, apesar dessas contradições, há que se destacar a atitude e a informação que alguns moradores foram construindo ao longo de diversas intervenções de instituições governamentais e não governamentais, o que tendeu a formar lideranças locais que apesar de passos ainda tímidos discutem sobre a importância da história local, da preservação dos patrimônios e valorização da cultura local, sendo fundamental fortalecer essa prática para que a relação dos moradores com o patrimônio em que residem e convivem cotidianamente ganhe uma dimensão mais positiva.

\section{Referências}

AZEVEDO FILHO, J.D.A.M. A produção e a percepção do turismo em Parintins. Tese doutorado- São Paulo: Faculdade de Filosofia, Letras e Ciências Humanas da Universidade de São Paulo, 2013.

BARRETTO, M. Cultura e turismo: discussões contemporâneas. Campinas/SP: Papirus, 2007.

BAUER, M. A popularização da Ciência como Imunização Cultural: Função de resistência das representações sociais. In. GUARESCHI, P.; JOVCHELOVITCH, S. (Orgs.), Textos em representações sociais (pp. 3159). Petrópolis: Vozes, 1995.

BRASIL. Ministério do Turismo. Plano Nacional do Turismo - diretrizes, Metas e Programas, 2003-2007. Brasília, abril de 2003.

COSTA, H. Cultura, trabalho e luta social na Amzônia: discurso dos viajantes- século 19. Manaus: Valer/FAPEAM, 2013.

FIGUEIREDO, S.L. Turismo e arqueologia na Amazônia-Brasil: aspectos de preservação e planejamento. Anais do II seminário da associação Brasileira de Pesquisa e Pós -Graduação em Turismo- ANPTUR,UAM 2007.

FUNARI, P.P. (org.). Turismo e patrimônio cultural. São Paulo: Contexto, 2001. 
GONÇALVES, J.R.S. O patrimônio como categoria de pensamento. Comunicação apresentada na mesa redonda "Patrimônios emergentes e novos desafios: do genérico ao intangível", 26ª Reunião Anual da Associação Nacional de Pós- Graduação em Ciências Sociais, Caxambu, 23 de out. 2002.

HARTOG, F. Tempo e patrimônio. Varia história. Belo Horizonte, v. 22, n. 36, jul./dez. 2006, p. 261-273.

HILBERT, P.; HILBERT, K. Resultados preliminares de pesquisa arqueológica nos rios Nhamundá e trombetas, Baixo Amazonas.(1975) Traduzido por SIMÔES, Mário. In: Boletin do Museu Paraense Emílio Goeldi, 1980.

JODELET, D. Madness and Social Representations. London: Harvester Wheatsheal, 1993.

LEITE, E. Turismo cultural e patrimônio imaterial no Brasil. São Paulo: INTERCOM, 2011.

LIMA, H.P.; MORAES, B.M. Arqueologia e Comunidades Tradicionais na Amazônia. Ciência e Cultura, v. 2, p. 39-42. São Paulo: Hucitec, 2013.

MACHADO, J.S. Arqueologia e História nas construções de continuidade na Amazônia. Bol. Museu Pará Emílio Goeldi. Ciências Humanas, Belém, v.4, n. 1, p. 57-70, jan-abr, 2009.

MARTINS, J.C.O. Turismo: entre o consumo, resgate psíquico e choques culturais, um objeto de estudo em construção. Anais da $57^{a}$ Reunião da Sociedade Brasileira Para o Progresso da Ciência e Tecnologia, 2008.

MARTIUS, C.F.P.V. "Como se deve escrever a história do Brasil". Revista do Instituto Histórico e Geográfico Brasileiro, 6 (24), jan. 1845, pp. 389-411.

MENESES, U.T.B. Premissas para a formulação de políticas públicas em arqueologia. In: LIMA, T.A. Patrimônio Arqueológico: 0 desafio da preservação. Revista do Patrimônio Histórico e Artísitico Nacional, n.33, 2007.

MOSCOVICI, S. Representações Sociais: investigação em psicologia social. Petrópolis, RJ: Vozes, 2003.

NORA, P. Entre memória e história: a problemática dos lugares: Revista do programa de estudos de Pós graduação em História do Departamento de História da PUC-SP, São Paulo, n.10, p.7-28, 1993.

PAIM, E.A. Lembrando, eu existo. In: OLIVEIRA, M. (Coord.) História do Ensino Fundamental. Brasília:MEC/SEB, 2010.

PARDI, M.L.F. A preservação do patrimônio arqueológico e o turismo. In: LIMA, T.A. Patrimônio Arqueológico: o desafio da preservação. Revista do Patrimônio Histórico e Artísitico Nacional, n.33, Brasília, 2007.

PELEGRINI, S. O patrimônio cultural e a materialização das memórias individuais e coletivas. UNESP - FCLAs - CEDAP, v.3, n.1, p. 87, 2007.

REGO, N. Geração de ambiências: três conceitos articuladores. Educação, Porto Alegre, v. 33, n. 1, p. 46-53, jan./abr. 2010. 
Naia Maria Guerreiro Dias: Universidade Federal do Amazonas, Manaus, AM, Brasil.

E-mail: naia_dias@hotmail.com

Link para o currículo Lattes: http://lattes.cnpq.br/5148044834240281

Data de submissão: 28 de agosto de 2016

Data de recebimento de correções: 30 de janeiro de 2018

Data do aceite: 23 de março de 2018

Avaliado anonimamente 